\title{
Public-private collaboration and scientific impact: an analysis based on Danish publication data for 1995-2013 ${ }^{1}$
}

\author{
Carter Bloch*, Thomas K. Ryan and Jens Peter Andersen \\ *carter.bloch@ps.au.dk (corresponding author); tryan@ps.au.dk; jpa@ps.au.dk \\ Danish Centre for Studies in Research and Research Policy, Aarhus University, \\ Bartholins Allé 7, 8000 Aarhus C., Denmark.
}

\begin{abstract}
In the past few decades, there has been increasing interest in public private collaboration, which has motivated lengthy discussion of the implications of collaboration in general, and co-authorship in particular, for the scientific impact of research. However, despite this strong interest in the topic, there is little systematic knowledge on the relation between public private collaboration and citation impact. This paper examines the citation impact of papers involving public-private collaboration in comparison with academic research papers. We examine the role of a variety of factors, such as international collaboration, the number of co-authors, academic disciplines, and whether the research is mainly basic or applied. We first examine citation impact for a comprehensive dataset covering all Web of Science journal articles with at least one Danish author in the period 1995-2013. Thereafter, we examine whether citation impact for individual researchers differs when collaborating with industry compared to work only involving academic researchers, by looking at a fixed group of researchers that have both engaged in public-private collaborations and university-only publications. For national collaboration papers, we find no significant difference in citation impact for public-only and public-private collaborations. For international collaboration, we observe much higher citation impact for papers involving public-private collaboration.
\end{abstract}

Keywords: Co-authorship, Public-private collaboration, International collaboration, Citation impact, Bibliometrics

\footnotetext{
${ }^{1}$ This paper draws on earlier work in the project Collaboration in Research, including Bloch, Ryan, \& Andersen (2016) and Bloch, Andersen, Ryan \& Schneider (2017). Financial support from the Danish Agency for Science, Technology and Innovation is gratefully acknowledged.
} 


\section{Introduction}

In the past few decades, there have been substantial increases in public-private collaboration. This includes both formal collaboration and interactions of a more informal nature (Perkmann et al. 2013). Parallel to this has been strong increases in the number policies to promote public-private collaboration, both in terms of research policy that promotes the so-called third mission activities of universities, commercialization and entrepreneurialism in general, and in terms of innovation policy that encourages companies to engage in interaction with public research.

Public-private research collaboration can be seen both from the perspective of universities and from that of business ${ }^{2}$. Research has shown that academic researchers' motivations to collaborate with business may vary greatly, from a more 'entrepreneurial logic' that focuses on technology development and commercialization, to a more 'academic logic' that reflects many of the traditional values of the scientific system (D’Este \& Perkmann, 2011).

Research collaboration may have a number of potential benefits, such as division of labor, knowledge transfer and combinations of different perspectives, network access and greater visibility, but organizing and engaging in collaboration may encounter increased costs in time and financial resources (Katz \& Martin, 1997). Among the potential benefits for public-private collaboration in particular are a greater utilization of academic research in business innovation, knowledge transfer and exchange, mutual learning, and a greater alignment of academic and business research. The latter can be seen in a positive light as a 'hybrid system' (Owen-Smith, 2003) in which there are important feedbacks and synergies between academic and entrepreneurial research. However, this entrepreneurial influence on academic research agendas has also been highlighted as an important danger of the entrepreneurial university. A main concern here is that a shift in focus towards bridging academic and entrepreneurial research will detract from focus towards the type of 'blue-skies' research that often lies behind significant scientific breakthroughs (Etzkowitz, 2003). This motivates the concern that an overly short-term focus on reaping the benefits of research now may ultimately result in a slowing of the growth of scientific knowledge. Connected to this are a number of other potential, negative implications, such as an excessive shift from fundamental to applied research, less academic freedom (Behrens \& Gray, 2001), manipulation of science for short term gain (Slaughter \& Leslie, 1997) and restrictions on the diffusion of open knowledge.

However, differences between purely academic and public-private collaboration are not always clear. Perkmann and Walsh (2009) find in their qualitative study of university-industry collaboration in the engineering sciences that research far from application is more likely to be published while research close to application is more likely to be irrelevant for the scientific community or suffer from secrecy concerns. Therefore, we would expect that co-authored papers with industry are often a result of what they call knowledge generation projects. This suggests that co-authored papers may often be a result of traditional research projects, and thus, with impact similar to that of other co-authored papers.

Both research collaboration in general and public-private collaboration in particular have been the study of a wide range of literature, approaching the topic from a number of angles. Bozeman et al. (2013) review the topic of research collaboration from the perspective of the individual university researcher, with focus on aspects such as the attributes of collaborators, collaborative process and organization characteristics as the affect collaboration choices and outcomes. Perkmann et al. (2013) review the literature that focuses on public-private collaborations themselves, and the various forms of academic engagement in these interactions.

\footnotetext{
${ }^{2}$ For a comprehensive review of the literature on research collaboration, see Bozeman, Fay and Slade (2013). 2
} 
Our focus in this paper is more specifically on collaboration in the form of co-authorships and the relation between public-private co-authorship and scientific impact. Co-authorship has long been advocated and used as a measure of research collaboration, though at the same time recognizing its limitations (Katz \& Martin, 1997). Its advantages include verifiability, data availability, ease of measurement, and quantifiability that allows analysis that would not be possible with more qualitative forms of data. However, it can at best be considered as only a partial measure of research collaboration. Co-authorship can both be viewed as one of many different forms of output of collaboration, and at the same time as a diffuse measure, where we do not know the nature and intensity of interaction of individual co-authors behind papers. These limitations notwithstanding, there is still substantial interest in different forms of co-authorship and their relation to scientific impact. Analysis of this relation can both inform issues concerning the importance of collaboration and contribute to better understanding of the relation between collaboration and citation impact, which is particularly important given the widespread use of bibliometric and citation based indicators.

There is now widespread evidence that co-authored papers are on average more highly cited than papers with a single author, and that papers involving international collaboration are even more highly cited (Glänzel \& Schubert, 2001; Persson, Glänzel, \& Danell, 2004; Sørensen \& Schneider, 2017; Van Raan, 1998). However, there is much less evidence on the citation impact for public-private collaboration in particular. Historically, research collaboration has increasingly become the norm in research, with the difference in citation frequency between multiple and single author papers increasing over time (Wuchty, Jones, \& Uzzi, 2007). However, at the same time, the marginal effect of increases in the number of authors appears to be diminishing (Larivière, Gingras, Sugimoto, \& Tsou, 2015).

Godin and Gingras (2000) find for Canada that journal factor impact for interpectoral collaboration research is on average not lower than for university research collaboration. However, it is unclear whether a similar result holds for the citation impact of papers. Katz and Hicks (1997) find for the UK that the number of citations per paper are increasing in the number of co-authors, number of collaborating institutions, foreign collaboration, and industry collaboration. However, this early study was not able to analyse or control for field differences. Liu et al. (Liu, Chang, \& Chen, 2012) find for Taiwan that in general, international collaborations have higher citation impacts than domestic collaborations.

Lebeau, Laframboise, Larivière \& Gingras (2008) examines this using data for Canada for the period 1980-2005 and finds that while public-private collaborations are on average published in lower impact journals, they receive on average higher (field normalized) citation counts than for university only or industry only papers. However, they do not control for confounding variables, such as number of authors and whether the co-authors are from Canada or abroad. The, comparison thus, stays at a descriptive level, where it is difficult to discern to what extent the higher impact is related to a higher number of authors, the internationality of the paper or the fact that industrial actors have been involved.

This paper examines the citation impact of papers involving public-private collaboration in comparison with academic research papers. We ask whether publications with industrial co-authors have different expected impact than publications with only public research organizations - thus, we ask whether there is an added academic value to industrial collaboration. In comparing public research with public-private collaboration, it is unclear whether we are comparing the same types of articles, for example concerning the nature of the research and the ability of researchers involved. In other words, there are a number of factors that complicate making a valid comparison. In this paper, we will seek to control for a variety of these factors. In particular, we examine the role of the number of co-authors, academic disciplines, and whether the research is mainly basic or applied.

It has been shown that citation impact is positively associated with the number of co-authors, hence differences in the average number of co-authors for different forms of collaboration can influence comparisons. One extreme example is to what degree extremely large consortiums of co-authors, such 
as those within high-energy physics, influence comparisons, or whether there are large differences in the distribution of disciplines across types of collaboration. Self-citations can be removed, though selfcitation may in turn have an amplifying effect by creating more visibility of research and thereby more potential (non-self) citers (Van Raan, 1998).

A key factor that has received much attention is controlling for differences in citation behavior across fields (Waltman, 2016). Field-normalised measures of citation impact control for these differences to a large degree, but may not fully be able to account for differences in citation behavior among applied vs. more fundamental research within specific disciplines. The latter basic-applied distinction is particularly difficult to classify systematically, and we will rely on a rough proxy based on the journal for the publication and on the set of journals cited by each paper within the medical sciences that attempts to distinguish between clinical research and basic biomedical research.

An additional dimension that we examine is international collaborations in comparison with national collaboration. These two dimensions, public-private and national-international, are used to create a classification of collaborations types

Finally, we examine whether citation impact for individual researchers differs when collaborating with industry compared to work only involving academic researchers, by looking at a fixed group of researchers that have both engaged in public-private collaborations and university-only publications. This methodology reduces the potential bias of high performing researchers selecting into public-private collaborations more often than low performing researchers do.

The analysis is conducted based on publications in Web of Science with at least one Danish address over the period 1995-2013. The analysis covers a dataset of 183,812 journal articles. We identified academic and industrial authors using a combination of systematic algorithms and manual coding. In order to control for the above factors in our comparison, three sets of analyses are conducted: a descriptive analysis of mean normalized citation scores (MNCS) across different forms of collaborations; a multivariate regression analysis of the role of these factors for normalized citation scores; and a comparison of citation impact for different forms of collaboration for a fixed set of researchers that have engaged in each type of collaboration.

\section{METHOD and DATA}

We examine both whether collaborations are among companies and public research (public-private collaborations) and whether collaborations are national or multinational. We utilize the following classification consisting of five mutually exclusive publication types:

\section{Type 1: National public research}

Danish public research organization (university or government research institute; no industry);

Type 2: Multinational public research

Danish and international public research organizations (no industry)

Type 3: National public-private research

Collaborations between Danish public research organizations and Danish companies (no international partners);

Type 4: Multinational public-private research

International public-private collaborations - public-private collaborations with at least one international partner

Type 5: Industrial research

Industry only (Danish companies, potentially also including foreign companies)

The relationship between the five types is illustrated in Table 1 . We use this categorization to distinguish between different types of publications in relation to the national-international and public-private 
distinction. We analyze in two parts whether the citation impact of papers differ depending on the type. The first part analysis examines this at a macro level while the second part examines this on a micro level.

Table 1. Overview of collaboration types by organization type and internationality. Public research organizations are shortened as PRO.

\begin{tabular}{llll}
\hline & PRO (Only) & Industry \& PRO & Industry (Only) \\
\hline National & Type 1 & Type 3 & \\
Multinational & Type 2 & Type 4 & Type 5 \\
\hline
\end{tabular}

\subsection{Measuring citation impact}

We use data from CWTS' in-house version of Clarivate Analytic's Web of Science citation indices (CIWoS). The CWTS in-house version of the WoS database indicates whether individual publications include an author from private industry and whether the publication is an international collaboration involving authors from two or more countries. In general, a fixed three-year citation window was used to calculate citation impact. However, for the multivariate regression analysis, a variable length window of three or more years was used to reduce the number of articles with no citations (this point is discussed in greater detail below).

We have enhanced this data by manually validating and classifying all Danish addresses (public research institution, private business or other public organisation). A systematic algorithm was used to identify universities, other public research institutions and private businesses. All remaining organisations with Danish addresses were manually coded into three categories: public sector research organization or other public sector organization ${ }^{3}$, private business, and unknown. In all, 6,133 Danish organization names were coded manually. Unknown names were disregarded in the categorization of collaboration types for articles, and the article itself was removed from the analysis if institution type could not be identified for any of the co-authors. The involvement of foreign businesses was validated using CWTS indicators of industry co-authorship.

The analysis relies in particular on the mean normalized citation score (MNCS). The MNCS indicator is obtained by averaging the normalized citation scores (NCS) of all publications of a unit or grouping. If a unit has an MNCS indicator of one, the publications of the unit have been cited on par with world averages (or more precisely, database averages) for similar publications in terms of field and publication year. An MNCS indicator of, for instance, two means that on average the publications of a unit have been cited twice as frequently as the world average of that field, the same year as the paper is published (Waltman et al., 2012). Average field citation rates depend heavily on the field classification used. Although parts of the analysis presented in this paper uses a very broad categorization of just ten fields, grouping Web of Science journal categories together, we use a different classification system for the normalization. The article-specific classification by Waltman \& Van Eck (2013) takes into account referencing practices influencing the speed and abundance of bibliographic references, allowing a more granular and exact normalization of the individual item (Lundberg, 2007) than journal-based categorizations.

There may be cases where single collaborations involving a very large number of authors strongly influence MNCS for the individual author. A method to reduce the influence of single papers involving extremely large collaborations is to fractionalize citation scores by the number of authors. Hence, we utilize both full and fractional counts of the MNCS indicator (Waltman \& van Eck, 2015):

\footnotetext{
${ }^{3}$ Other public sector organisations were initially coded separately, but this group did not prove large enough to be analysed on its own, and in many cases was difficult to distinguish from public sector research organisations. Based on this, the two groups were combined. 


$$
\text { Full count MNCS }=\frac{\sum N C S_{i}}{p} ; \text { Fractional count MNCS }=\frac{\sum \frac{N C S_{i}}{n_{i}}}{\sum \frac{1}{n_{i}}}
$$

Where $\mathrm{NCS}_{\mathrm{i}}$ is normalized citation score for paper $\mathrm{i}, \mathrm{p}$ is number papers, and $\mathrm{n}$ is number authors for paper $\mathrm{i}^{4}$.

Citation data is typically highly skewed, with a large number of articles with a small number of citations and a small number with a very high number of citations. For this reason, it is important that averages are calculated for large groups of papers, minimizing the sensitivity to extreme outliers. To improve the robustness of results, instead of calculating citation based indicators for each individual year, we have constructed indicators for four time periods of 4 to 5 years, ie. from 1995-1999, 2000-2004, 2005-2009 and 2010-2013.

\section{Descriptive Statistics}

For the period 1995-2013, there are in total 189,703 journal articles in the WoS database that have at least one Danish address. Figure 1 shows developments in Danish journal articles over time, from 1995 to 2013, classified into five broad categories, National public research, multinational public research, national public private research, multinational public-private research and industrial research.

The total annual number of Danish journal articles in WoS has increased dramatically from 6,738 in 1995 to 16,351 in 2013. Growth has been particularly strong in the last 10 years, where the total number of articles has increased by $87 \%$. The far majority of publications are public research papers. In particular, international public research has increased almost four-fold over the period and now accounts for over half of all publications. The share of journal articles involving public-private collaboration increased from $7.8 \%$ in 1995 to $11.9 \%$ in 2010 . Since 2010, the share has fallen slightly, with the share at $10.5 \%$ in 2013 . In all, the share of total publications involving some form of international collaboration (including both pure public and public-private collaborations) has increased from $39 \%$ in 1995 to $61 \%$ in 2013. Among public-private collaborations, the share of papers involving international collaboration has also risen, from $68 \%$ to $75 \%$ over the same period.

\footnotetext{
${ }^{4}$ An example: suppose there is one paper with one author and NCS=1 and one paper with three authors and NCS=2. Full count MNCS for these two papers is 1.5 and fractional count MNCS is 1.25. 


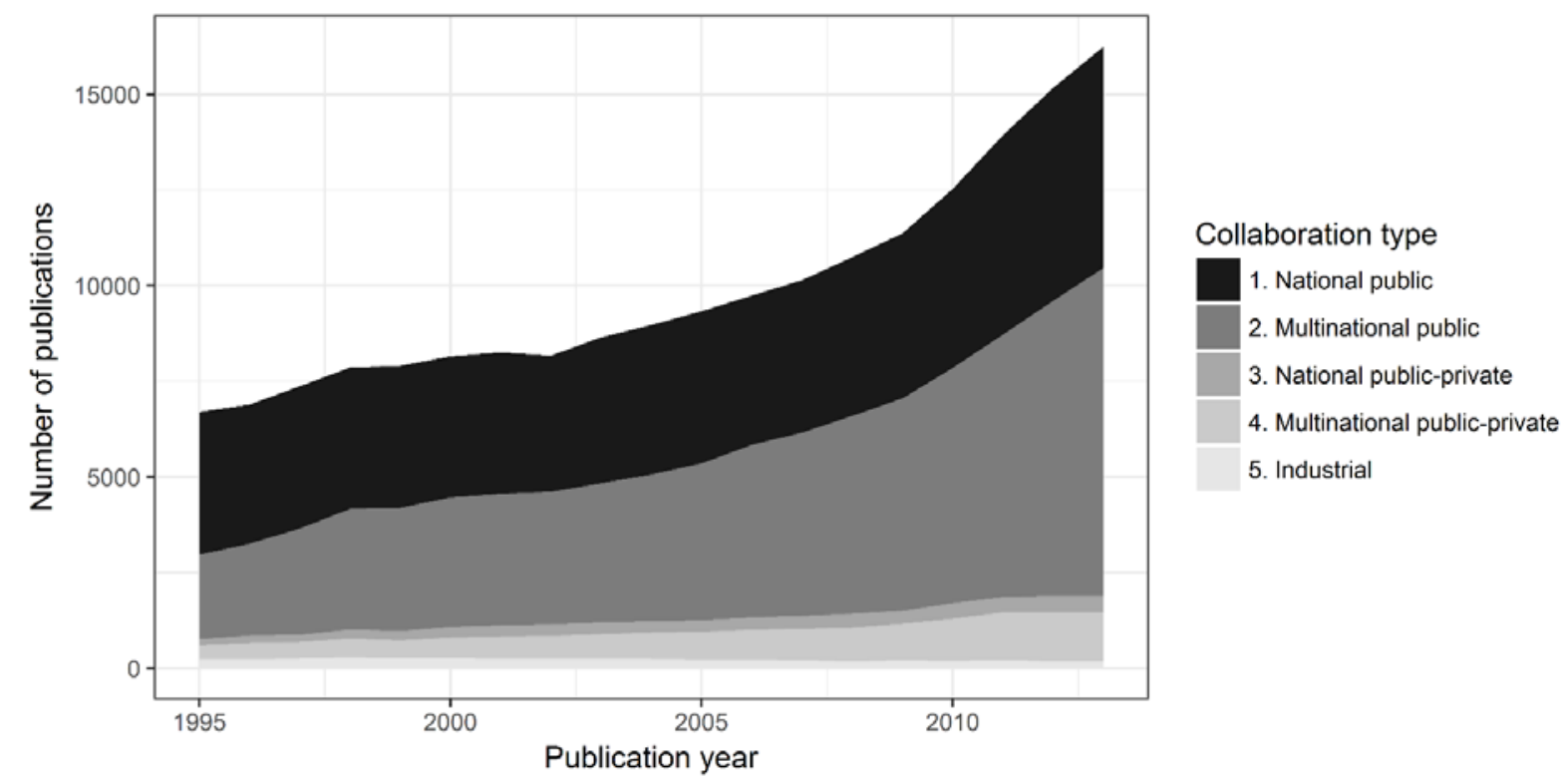

Figure 1. Distribution of collaboration types over time for Danish research, 1995-2013. Danish public research only and industry only also include solo articles with no co-authors. Public-private collaboration includes both Danish and international collaborations.

National public research and Industrial research include papers with single authors. In both cases, the share of solo papers has declined greatly over time. The share of National public research papers with single authors has declined over the period from $26 \%$ in 1995 to $15 \%$ in 2013, while the share of industrial research papers with a single author has fallen from 36\% (68 out of 187) in 1995 to $18 \%$ (15 out of 84) in 2013.

It should also be noted that there has been strong growth in the global, total number of journal articles in the WoS database, which can likely explain part of the development in the articles and collaboration. In the period from 1995 to 2013, the total annual number of articles has increased by 113\% (based on own calculations) in comparison to $143 \%$ in our sample covering Danish authors. The growth in WoS is driven by two factors: strong global increases in research publication activity, particularly in Asia but also in Denmark and other western countries; and increases in the number of journals included in the database (in particular in 2006, where a large number of additional journals were included in the WoS database). The latter has large importance for many Asian countries, but is less important in relative terms for countries like Denmark, whose primary publication channels are already included in WoS. However, it is clear that this growth in journal coverage has had some degree of influence on the overall growth of journal articles (with a Danish address) in WoS. On the other hand, it should be expected that increases in publication activity lead to an expansion in the number of journals used, since most journals have a fixed number of articles that they can publish each year (though minor increases are possible through increases in the annual number of issues). The increase in data coverage in the databases does not seem to exceed the development in collaboration.

Figure 2 shows MNCS for different forms of collaboration involving Danish public research. As mentioned above, these indicators are normalized both across fields and according to global (database) averages. Overall, citation impact for Danish research is high in international comparison, with Denmark ranking among the top five countries in average citation impact (Danish Ministry of Higher Education and Science, 2018). As the figure shows, MNCS for all articles with at least one Danish public research co-author was 1.3 in 1995-1999 and has gradually increased over time, reaching 1.5 in 2010-2013. This same upwards trend can be found in many of the other top performing countries. 
Generally speaking, and among papers involving Danish public research, MNCS is lowest for papers only involving Danish public research. Taking the entire period into account, national public-private collaborations have typically had a slightly higher MNCS, though the difference is not large and in fact MNCS for Danish public research papers is slightly higher in 2010-2013, 1.2 compared to 1.1.

When examining these figures, it is important to take into account overall developments in research production, where there is a growing shift towards international collaboration. It may very well be the case that many research projects and papers that would have been conducted nationally 15-20 years ago are now performed with the involvement of international partners. And, it may also be the case that these papers tend to be above average in terms of performance.

Moving along, MNCS for international collaborations only involving public research is higher than national collaborations, at around 1.5 for much of the period and 1.6 in 2010-2013. Hence, in this last period, (field-normalised) citation impact is around $40 \%$ higher for these international public collaborations than for national collaborations.

As Figure 2 clearly shows, by far the highest citation impact is found for international, public-private collaborations involving multiple partners. In the figure below, we show impact for all international multi-partner collaborations that include industry. Over the period, MNCS ranges from 2.2 to 2.5 in the last period. The latter implies citation impact that is $247 \%$ higher than world averages. These results thus also show that international papers involving public-private collaboration have on average substantially higher impact than international collaborations only involving public research organisations. This raises a number of further questions. For example: Are the topics or types of research that these papers cover different, having a greater importance and attracting greater attention? Do they more often involve top researchers? Is there something about the synergies of the collaboration that produces higher impact papers? Are the results driven by a small group of very influential papers involving an extremely large number of co-authors? The remainder of this paper, attempts to qualify the discussion through both a macro and micro level analysis of impact and collaboration.

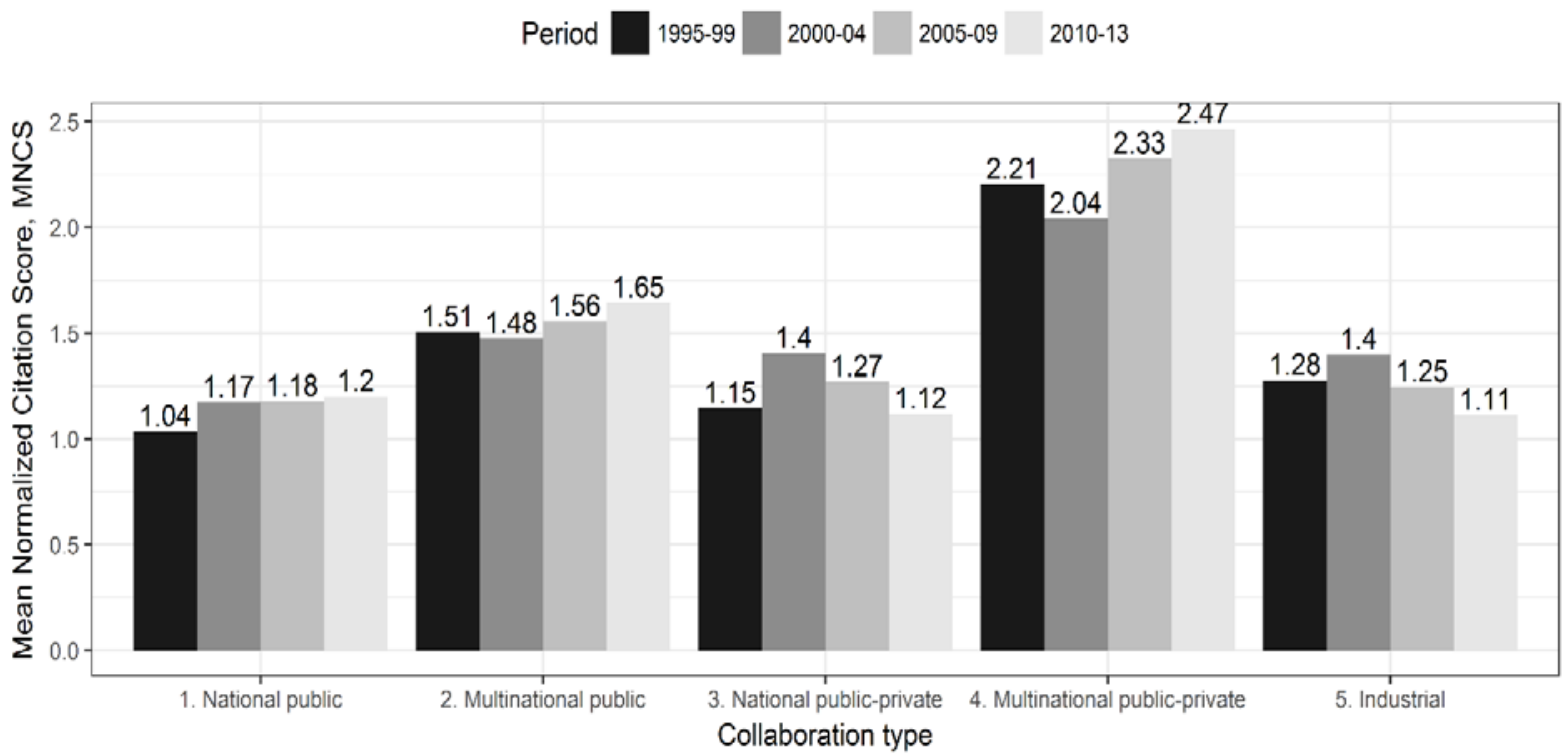

Figure 2. Mean Normalized Citation Score (MNCS) for different types of collaboration, 1995-2013. Based on publications with at least one Danish address. 


\section{Article level regression analysis}

In the regression below, we analyze the relationship between the public-private as well as nationalmultinational with citation impact. Highly skewed citation distributions are problematic for OLS regression, and Thelwall \& Wilson (Thelwall \& Wilson, 2014) suggest using the logarithm of citations plus one (to allow inclusion of uncited publications), as this is shown to give consistent estimates. We would argue that this method fits even better for normalized citation data because normalized citations tend to follow a continuous lognormal distribution. In the descriptive analysis above, where we also examine developments over time, citation scores were calculated using a fixed three year window. In contrast, we have chosen here to allow citation windows to vary according to the number of years available, while at the same time using year dummies to account for differences in average citation impact over years. Our main reason behind this choice is to reduce the number of papers with zero citations and at the same time increase the scope of citation activity that the regression analysis examines. Hence, the dependent variable in the regressions is the log of $(\mathrm{NCS}+1)$.

As described in the methods, field-normalization is based on a finely granulated article-level classification system, however, we summarise results here in 10 fields based on the 257 subject classes used by Thomson Reuters: Biology, Chemistry, Health Sciences, Biomedicine, Engineering \& Materials Sciences, Physics \& Mathematics, Agriculture, Fisheries \& Forestry, Geosciences, Social Sciences \& Humanities, and Multidisciplinary, derived from NordForsk (NordForsk, 2014). Field dummies are created based on these categories. We also conduct the regressions for individual fields to examine potential field differences in the relation between citation impact and types of collaboration. Finally, within the medical sciences, the constructed fields provide a rough distinction between clinical research (Health Sciences) and basic research (Biomedicine).

The number of authors is generally known to be highly related to the number of citations a publication receives. Also after removing self-citations. The reason can be that there are benefits to being many authors, that the number of authors correlates with other variables that affect impact and the self-citations have an increasing effect - i.e. two self-citations lead to more than double the amount of self-citations that do one self-citation. Simply removing self-citations does not control for the marketing effect of selfcitations. And to allow for a possible non-linear relationship between the number of authors and citation impact, we also include the square of the number of authors in regressions.

We control for the number of authors, year of publication and field. Regressions 2-6 are on the level of fields. The regressions mirror the descriptive statistics above, however, the differences are smaller, when we control for number of authors.

The main explanatory variables in the analysis are for types of collaboration. Dummy variables have been created for:

- Whether at least one author is from a Danish private business (dk_indu)

- Whether at least one author is from a foreign private business (int_indu)

- Whether at least one author is from a foreign university (int_univ)

- Whether there is both at least one author from a foreign private business and one author from a foreign university (intl_indu_uni)

These dummy variables are not mutually exclusive and allow us to compare the citation impact of different forms of collaboration, while at the same time controlling for other factors.

Hence, the explanatory variables included in the regressions are: number of authors, number of authors squared, dummies for collaboration types, field dummies and year dummies. The regressions are first conducted for all fields and thereafter for each individual field that accounts for at least $10 \%$ of total articles. 
Table 2 shows descriptive statistics for the dataset. For each type of collaboration, the table shows the distribution of articles across fields, MNCS, the average number authors per paper, and total number of publications. As noted above, the number of pure industry papers is extremely low and has been declining over the period from 1995-2013. Hence, the far majority of papers co-authored by industry are done in collaboration with public research. There are about 7,000 papers each with (only) national public-private collaboration and with multinational public-private collaboration. As expected, the average number of authors per paper is higher for international collaborations, particularly for multinational public-private collaborations. The distribution of articles across fields varies according to type of collaboration. Health sciences has the highest share of publications in total (37\%) and has its highest shares in national public and multinational public-private collaborations. Shares are highest for biomedicine in national and multinational public-private collaborations. Engineering \& materials has highest share among national public-private, while physics \& math is highest within multinational public.

Table 2. Distribution of publications across fields (above horizontal rule), MNCS, number of authors (n_authors) and number of publications (n_pub) for different collaboration types, 1995-2013.

\begin{tabular}{|c|c|c|c|c|c|c|}
\hline & Total & $\begin{array}{c}\text { National } \\
\text { public }\end{array}$ & $\begin{array}{l}\text { Multi- } \\
\text { national } \\
\text { public }\end{array}$ & $\begin{array}{l}\text { National } \\
\text { public- } \\
\text { private }\end{array}$ & $\begin{array}{c}\text { Multi- } \\
\text { national } \\
\text { public- } \\
\text { private }\end{array}$ & Industrial \\
\hline Chemistry & 0.09 & 0.08 & 0.08 & 0.14 & 0.10 & 0.09 \\
\hline Health_ciences & 0.37 & 0.40 & 0.33 & 0.24 & 0.38 & 0.22 \\
\hline Biomedicine & 0.23 & 0.21 & 0.24 & 0.33 & 0.34 & 0.14 \\
\hline Engineering \& materials & 0.12 & 0.12 & 0.10 & 0.22 & 0.13 & 0.27 \\
\hline Physics \& mathematics & 0.15 & 0.12 & 0.19 & 0.09 & 0.10 & 0.15 \\
\hline Agriculture, fisheries \& forestry & 0.11 & 0.12 & 0.10 & 0.19 & 0.10 & 0.26 \\
\hline Geosciences & 0.05 & 0.04 & 0.06 & 0.03 & 0.03 & 0.07 \\
\hline Multidisciplinary & 0.02 & 0.01 & 0.03 & 0.01 & 0.02 & 0.01 \\
\hline Social sciences & 0.05 & 0.06 & 0.03 & 0.01 & 0.00 & 0.04 \\
\hline MNCS & 1.42 & 1.18 & 1.71 & 1.25 & 2.13 & 1.24 \\
\hline n_authors & 11.24 & 3.67 & 16.75 & 5.03 & 71.04 & 4.19 \\
\hline n_pub & 183812 & 99865 & 69979 & 6836 & 6936 & 196 \\
\hline
\end{tabular}

\subsection{Regression Results}

The results of the regressions are shown in Supplementary Table S 1 . Table S 1 reports coefficient estimates for the OLS regression on $\log (\mathrm{NCS}+1)$ as well as $95 \%$ confidence intervals. Figure 3 shows the estimated factor effects of the main variables. Coefficients from the main regression are transformed to be interpreted as factor effects on NCS +1 and include $95 \%$ confidence intervals. Thus, int_univ is 1.216 in figure 3 ( 0.189 in regression) it means that if an article is authored by an international author the expected NCS +1 of that article increases by a factor of 1.216 or by $21.6 \%^{5}$. In figure 3 , results are shown for the full sample covering all fields, and individually for each field with over $10 \%$ of observations. In the following sections, we report the regression coefficients as well as the transformed percentage effects on ncs +1 .

A result that holds both in total and for individual fields is that citation impact is increasing in the number of authors but that this relation diminishes as the number of authors grows (ie. decreasing in authors 
squared). These results thus correspond well with earlier studies (e.g. Larivière et al., 2015; Wuchty et al., 2007). However, coefficient size is very small for the number of authors and its square (sq_authors), as can be seen from Figure 3.

\subsubsection{Domestic-international dimension}

The regression results indicate that international collaboration with university researchers outside Denmark is associated with a higher expected impact. If a research publication with a Danish author has an author from a university outside Denmark, the expected impact (NCS+1) is approximately $21.6 \%$ higher than an article without international authors. This reiterates the many empirical studies that have found that international collaborations tend to have a higher impact than domestic collaborations (e.g. Glänzel \& Schubert, 2001; Sørensen \& Schneider, 2017; Van Raan, 1998).

Whether this relationship relates to impactful researchers collaborating more with international colleagues and/or to international collaborations in and of themselves giving rise to extra benefits is not apparent in this regression.

This finding is consistent among all fields except chemistry where surprisingly there seems to be a negative relationship. This result within chemistry is somewhat puzzling, but it appears to at least be partially driven by higher impact among the top $1 \%$ for national papers compared to papers co-authored with international researchers. If we for example remove papers with NCS greater than $5(0.6 \%$ of publications within chemistry) then the coefficient for international public research is still negative but is reduced by half and is insignificant. Additionally, the relationship is quite weak in Physics and mathematics - which may relate to the fact that most publications within physics are international collaborations.

\subsubsection{Public-Private dimension}

The regression indicated that overall, collaboration with international industrial authors as well as international university authors is associated with a higher expected impact, while the additional expected impact of collaborating with Danish industry is small or even slightly negative, depending on the field.

Concerning collaboration with Danish private business, there is a lot of variation in results across fields. Coefficient estimates are positive and significant within physics and mathematics and engineering and materials, and negative within both medical fields (health sciences and biomedicine). Overall, and within chemistry and agriculture, the coefficient is insignificant.

In contrast, collaboration with a foreign business is positive and significant in almost all cases (only exception being agriculture). Figure 3 shows that for all sciences, that the expected impact measured of a publication is $18.5 \%$ higher for articles with international industrial authors and Danish authors compared to only publications with only Danish authors.

The interaction of international public research and international industry is included in order to see whether there is an extra boost in citation impact for multi-partner collaborations involving both of these types. The number of publications with both of these types of collaborations is small compared to other groups of publications, leading to wide confidence intervals. However, despite this, coefficients for all fields is clearly positive and significant. Interestingly, this result appears however to be driven by only one field, health sciences. 


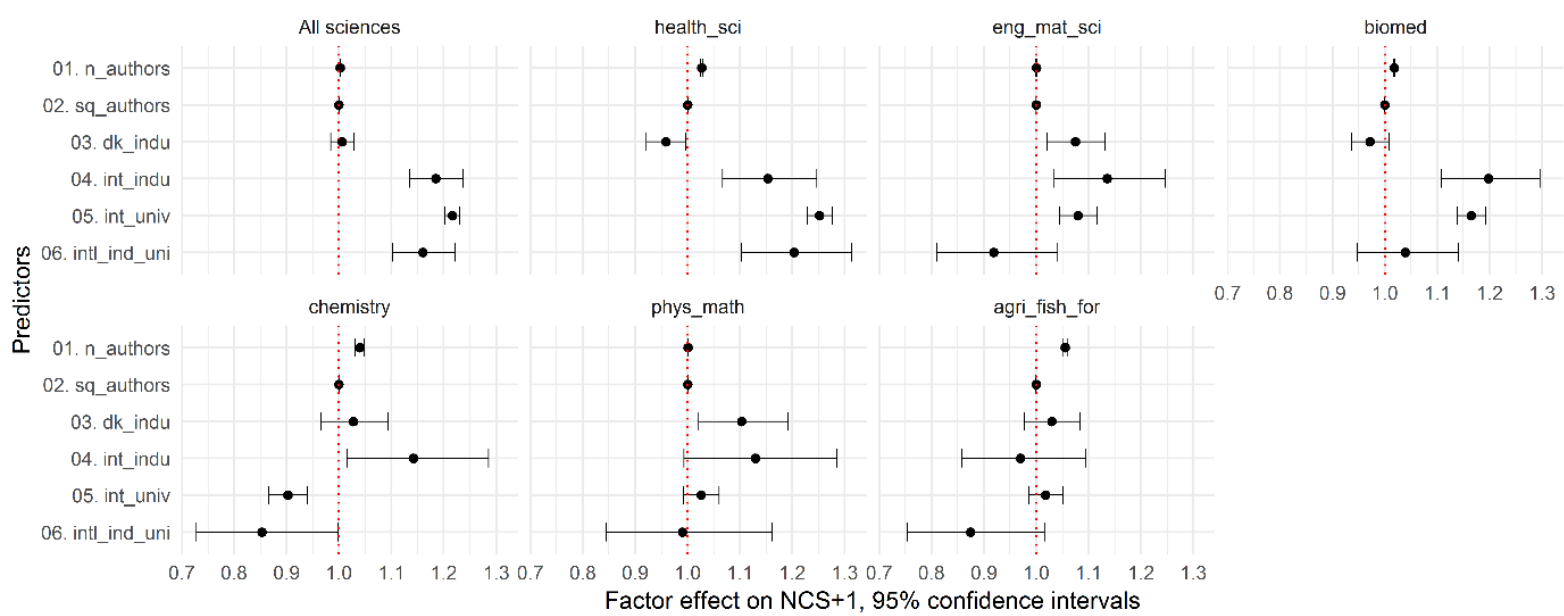

Figure 3. The main predictors for (NCS+1) as estimated factor effects. Transformed from regression by taking the exponential of estimated coefficients on log(NCS+1) in OLS regressions. Results are divided into seven models containing all sciences and the six most prominent research areas. See Supplementary Table $S 1$ for estimated coefficients.

\subsubsection{Selection bias}

There are many reasons we cannot assume a causal relationship between the independent and dependent variables. One of these is selection into international and industrial collaborations; if successful researchers are more likely to collaborate with industry and international partners we would also expect that the research produced would be above average. Thus, the researchers' ability is the driver of the observed effects. In the next analysis, we attempt to investigate whether this can explain some of the observed differences.

\section{Analysis at the level of the individual researcher}

The goal of this sub-section is to examine to which degree the impact of public-private collaboration can be explained by selection bias, where firms choose to collaborate with high performing researchers. We identify a group of corresponding authors of articles involving both public-private collaboration and public research collaboration and construct a list of all articles authored by the group of researchers within a period of time. In doing so, we are able to see how articles with public-private collaboration compare to academic-only articles authored by the same researchers.

The sample examined in this paper consists of all corresponding authors with a Danish address with an article in 2008-2010 involving public-private collaboration, which amounts to 798 researchers $^{6}$. For each of the 798 researchers, publication portfolios over the period 2006-2012 were collected in the Science and Social Science Citation Indices of Web of Science (WoS) using a name disambiguation algorithm developed by CWTS that has generally shown very high recall rates (90-95\%) especially with sets of non-Asian author names and affiliations (Caron \& van Eck, 2014) ${ }^{7}$. However, it is still important to note that this process is not perfect where both incomplete lists and false positives are possible. We limit the analysis to papers that have at least two co-authors, in order to compare the type of collaborative articles. Single authored papers will only appear in Type 1, and since we know that the number of authors is related to citation impact, we remove these from the analysis. Of these 798 researchers (and after

\footnotetext{
${ }^{6}$ Due to data availability, it is more feasible to match other publications with the corresponding authors than with other authors.

${ }^{7}$ The collection of individual publication portfolios was performed by CWTS, Leiden University. 
removal of single author papers), 51 had only one publication with collaboration during the period, which precludes the possibility of any comparison across types of collaboration. Hence, we removed them from the sample.

17,973 articles were identified over the period 2006-2012 for the 747 researchers. Table 3 shows the distribution of individuals according to number of publications.

Table 3. Distribution of individuals according to number publications.

\begin{tabular}{l|rrrrr|r}
\hline Number of publications by author & $2-5$ & $6-10$ & $11-19$ & $20+$ & Total & $\begin{array}{c}\text { Number } \\
\text { publications }\end{array}$ \\
\hline Number of authors & 177 & 133 & 161 & 276 & 747 & 17,973 \\
\hline
\end{tabular}

In general, citation impact is typically much higher for papers involving international collaboration. Hence, we want to take account of international collaborations in the analysis here, utilizing the classification of collaborations mentioned in the methods, except for type 5, industrial research.

We first conduct an aggregated analysis, where we calculate the mean normalized citation score (MNCS), for the entire subset of papers for each of these four types of collaboration. This subset of papers has in common that they include the same group of researchers as co-authors. However, it is clear that our approach here does not ensure that all co-authors are the same within each collaboration type, so this attempt to 'level the field' in terms of the researchers involved is only partially successful.

Secondly, we compare citation impact for the individual researcher. For each researcher covered in our sample, we calculate MNCS for the researcher's publications in each of the four categories. We make pairwise comparisons of different types of collaboration in order to ensure that we are comparing the same group of researchers. So, when we for example compare MNCS for Danish public research papers with Danish public-private collaborations, we only include researchers that have publications in both of these groups. In order to be as inclusive as possible, we only require that one publication is needed in a category in order to calculate the MNCS for the individual researcher.

Finally, it is important to keep in mind that this data is highly skewed, which calls into question the validity of tests that assume that the data is normally distributed. While there are differing opinions on how extreme the skewness should be before precluding the use of t-tests in practice, it may be more appropriate to use non-parametric tests that essentially test whether overall distributions for two groups are equal. In the following, we report results of both tests.

\subsection{Comparisons of means and medians}

The main results of this analysis are shown in Table 4. The table shows the results of pairwise comparisons of MNCS within the four types of collaborations. Industry only papers are not included here as only a small number of researchers have these papers and a comparison would thus not be generalizable in any meaningful way. 
Table 4. Comparison of mean and median values per individual-Results of non-parametric and parametric tests.

\begin{tabular}{|c|c|c|c|c|c|c|c|c|c|}
\hline & \multicolumn{4}{|c|}{ Full count MNCS } & \multicolumn{5}{|c|}{ Fractional count MNCS } \\
\hline & obs & Mean & Med. & $\begin{array}{l}\text { Sign- } \\
\text { Rank } \\
\text { (p-val) }\end{array}$ & $\begin{array}{l}\text { T-test } \\
(\mathrm{p} \text {-val) }\end{array}$ & Mean & Med. & $\begin{array}{l}\text { Sign- } \\
\text { Rank } \\
\text { (p-val) }\end{array}$ & $\begin{array}{l}\text { T-test } \\
\text { (p-val) }\end{array}$ \\
\hline $\begin{array}{l}\text { National public- } \\
\text { private }\end{array}$ & 545 & 1.243 & 0.821 & & & 1.235 & 0.805 & & \\
\hline National public & 545 & 1.212 & 0.983 & 0.011 & 0.677 & 1.188 & 0.979 & 0.018 & 0.759 \\
\hline Multinational public & 500 & 1.449 & 1.143 & 0.000 & 0.033 & 1.358 & 1.094 & 0.006 & 0.179 \\
\hline National public & 500 & 1.283 & 1.012 & & & 1.273 & 1.009 & & \\
\hline National public & 422 & 1.291 & 1.012 & & & 1.278 & 1.013 & & \\
\hline $\begin{array}{l}\text { Multinational public- } \\
\text { private }\end{array}$ & 422 & 2.200 & 1.227 & 0.000 & 0.001 & 1.979 & 1.161 & 0.000 & 0.008 \\
\hline $\begin{array}{l}\text { National public- } \\
\text { private }\end{array}$ & 472 & 1.272 & 0.844 & & & 1.262 & 0.831 & & \\
\hline Multinational public & 472 & 1.378 & 1.123 & 0.000 & 0.119 & 1.293 & 1.077 & 0.001 & 0.361 \\
\hline $\begin{array}{l}\text { National public- } \\
\text { private }\end{array}$ & 404 & 1.269 & 0.853 & & & 1.269 & 0.829 & & \\
\hline $\begin{array}{l}\text { Multinational public- } \\
\text { private }\end{array}$ & 404 & 2.217 & 1.226 & 0.000 & 0.001 & 1.997 & 1.155 & 0.000 & 0.008 \\
\hline Multinational public & 416 & 1.460 & 1.168 & & & 1.380 & 1.122 & & \\
\hline $\begin{array}{l}\text { Multinational public- } \\
\text { private }\end{array}$ & 416 & 2.215 & 1.251 & 0.008 & 0.006 & 1.986 & 1.204 & 0.057 & 0.018 \\
\hline
\end{tabular}

As noted above, comparisons are only made for researchers that have publications in both types of collaboration. For example, the first comparison is Danish public research papers vs. Danish publicprivate collaborations. Of the in all 747 researchers in the sample, 500 have at least one paper in each of these two groups. The table shows the average MNCS per researcher and median value of MNCS for this group of 500 researchers. We have conducted both standard t-tests and non-parametric SignRank tests on the data. P-values for the test statistics are shown in the table. The SignRank test is two-sided, while the t-test is one-sided (of whether the mean for the second group is significantly larger than the first).

Consider first the comparison of national public articles and national public-private articles. Interestingly, the mean value of MNCS for national public private is larger than for national public, but the median value is actually smaller. Mean values are fairly close to one another, and the test of the equality of the means is not rejected. In contrast, the SignRank test is significant, implying that the distribution of MNCS values for national public private is lower than for national public.

The comparison for other types of collaboration is more straightforward. For example, in comparison of National public articles with multinational public articles, multinational collaboration has both a significantly higher mean and the overall distribution is also significantly higher in terms of MNCS. The same result holds when comparing national public research with multinational public private. MNCS for multi-national public-private collaboration is clearly higher than for other collaboration types, and is thus in line with expectations from the regression results for the full sample of Danish research articles from 1995-2013. 
We can briefly summarize and simplify the findings for individual researchers. The expected impact of an article for individual researchers is lowest for National public research articles, only minutely higher impact can be expected from a national public private publication, whereas a multinational public publication has a higher expected impact and a multinational public private publication has highest expected impact. Thus, the results indicate that collaborating internationally and with industry is related to a higher expected impact. However, what should also be kept in mind is that no matter what type of co-authoring team the most common number of citations is zero.

\section{Conclusions}

In this paper, we have addressed the question of whether public-private collaboration is beneficial or detrimental to scientific research from various angles. For national collaboration papers, we find no significant difference in citation impact for public-only and public-private collaborations. For international collaboration, we observe much higher citation impact for papers involving public-private collaboration. This raises the question of whether it is the international collaboration rather than the public-private which adds to the increased impact. Furthermore, our results indicate that the observed differences are mainly driven by the health sciences, suggesting that citation impact is particularly high among articles based on large-scale clinical studies.

These observations are supported further by our regression analyses. Taking into account known factors influencing the citation impact of publications, as well as variation over time and field, the largest predictor is the presence of international collaboration. There is some variation across fields as to how large the effect of this predictor is, where the effect is largest in health science and biomedical research. At the same time, Danish research within agriculture, fisheries and forestry as well as physics and mathematics does not on average have large citation impact for this collaboration type. The effect of a private, international collaborator varies vastly across fields, which may in part be explained by the relatively low number of observations with international public-private collaboration.

As for the number of authors, a factor previously identified as a driver for citation impact, multinational and public-private collaborations tend to have a greater number of co-authors, and we find that citation impact is increasing in the number of co-authors. However, controlling for number of authors does not affect our basic results concerning relative citation impact for different types of collaboration.

Our findings on the differences between clinical and biomedical research could suggest a difference in citation and publication behavior for applied and basic research within a given field. These differences are not necessarily accounted for when field-normalizing citation scores, which do not differentiate between basic and applied work within a given field. A further investigation of this topic, however, would require a much more precise categorization of basic and applied research than the approximation used here.

The international dimension thus remains the strongest factor for citation impact. This reflects a number of factors, such as greater visibility and potential positive benefits on research from international collaboration. It may also reflect an increasing tendency among researchers to seek international collaboration, a trend that may be greater among the most promising researchers.

Bibliometric analysis of public-private collaboration only shows a limited perspective on the topic. There are other benefits and costs, tangible or not, associated with these collaborations. These are all relevant parts of an ongoing discussion in which our contribution should be seen as only one part of the puzzle.

In sum, one could ask what the implications of our analyses are for policy, where there is an ever increasing emphasis on promoting public-private collaboration in research. One concern is that a strong focus on public-private collaboration can be detrimental for researcher careers, as it may hurt their 
research performance, which is often measured in terms of citation impact. Our analysis does not show any indication that a focus on industry collaboration leads to lower impact. Impact for national public research and national public-private research are similar, and impact for multinational public-private research is very high. An alternative interpretation of our analysis is that promotion of international public-private collaboration leads to higher impact. Both international collaboration in general and multinational public and private research in particular are clearly associated with higher citation impact on average.

\section{References}

Behrens, T. R., \& Gray, D. O. (2001). Unintended consequences of cooperative research: Impact of industry sponsorship on climate for academic freedom and other graduate student outcome. Research Policy, 30(2), 179-199. http://doi.org/10.1016/S0048-7333(99)00112-2

Bloch, C. W., Andersen, J. P., Ryan, T. K., \& Schneider, J. W. (2017). Collaboration in Research. Copenhagen.

Bloch, C. W., Ryan, T. K., \& Andersen, J. P. (2016). Public-private collaboration and scientific impact: an analysis at the level of the individual researcher. In Proceedings of the 21st International Conference on Science and Technology Indicators (pp. 733-740). Valencia, Spain.

Bozeman, B., Fay, D., \& Slade, C. P. (2013). Research collaboration in universities and academic entrepreneurship: The-state-of-the-art. Journal of Technology Transfer (Vol. 38). http://doi.org/10.1007/s10961-012-9281-8

Caron, E., \& van Eck, N. J. (2014). Large scale author name disambiguation using rule-based scoring and clustering. In Proceedings of the Science and Technology Indicators conference 2014 (pp. 7986). Leiden, Netherlands: CWTS, Leiden University.

D’Este, P., \& Perkmann, M. (2011). Why do academics engage with industry? The entrepreneurial university and individual motivations. The Journal of Technology Transfer, 36(3), 316-339. http://doi.org/10.1007/s10961-010-9153-z

Danish Ministry of Higher Education and Science. (2018). Forskningsbarometeret 2017. Arlig statistik og analyse om forskning og innovation.

Etzkowitz, H. (2003). Research groups as "quasi-firms": The invention of the entrepreneurial university. Research Policy, 32(1), 109-121. http://doi.org/10.1016/S0048-7333(02)00009-4

Glänzel, W., \& Schubert, A. (2001). Double effort = Double impact? A critical view at international co$\begin{array}{llll}\text { authorship in } \quad \text { chemistry. } & \text { Scientometrics, } & \text { 50(2), }\end{array}$ http://doi.org/10.1023/A:1010561321723

Godin, B., \& Gingras, Y. (2000). Impact of collaborative research on academic science. Science and Public Policy, 27(1), 65-73.

Katz, J. S., \& Hicks, D. (1997). How much is a collaboration worth? A calibrated bibliometric model. Scientometrics, 40(3), 541-554. http://doi.org/10.1007/BF02459299

Katz, J. S., \& Martin, B. R. (1997). What is research collaboration? Research Policy, 26(1), 1-18. http://doi.org/10.1016/S0048-7333(96)00917-1

Larivière, V., Gingras, Y., Sugimoto, C. R., \& Tsou, A. (2015). Team size matters: Collaboration and scientific impact since 1900. Journal of the Association for Information Science and Technology, 66(7), 1323-1332. http://doi.org/10.1002/asi.23266

Lebeau, L. M., Laframboise, M. C., Larivière, V., \& Gingras, Y. (2008). The effect of universityindustry collaboration on the scientific impact of publications: The Canadian case, 1980-2005. Research Evaluation, 17(3), 227-232. http://doi.org/10.3152/095820208X331685

Liu, H. I., Chang, B. C., \& Chen, K. C. (2012). Collaboration patterns of Taiwanese scientific publications in various research areas. Scientometrics, 92(1), 145-155. http://doi.org/10.1007/s11192-012-0719-4

Lundberg, J. (2007). Lifting the crown - citation z-score. Journal of Informetrics, 1(2), 145-154. http://doi.org/10.1016/j.joi.2006.09.007 
NordForsk. (2014). Comparing Research at Nordic Universities using Bibliometric Indicators : Second report, covering the years 2000-2012. Oslo.

Owen-Smith, J. (2003). From separate systems to a hybrid order: Accumlative advantage across public and private science at Research One universities. Research Policy, 32(6), 1081-1104.

Perkmann, M., Tartari, V., McKelvey, M., Autio, E., Broström, A., D’Este, P., ... Sobrero, M. (2013). Academic engagement and commercialisation: A review of the literature on university-industry relations. Research Policy, 42(2), 423-442. http://doi.org/10.1016/j.respol.2012.09.007

Perkmann, M., \& Walsh, K. (2009). The two faces of collaboration: Impacts of university-industry relations on public research. Industrial and Corporate Change, 18(6), 1033-1065. http://doi.org/10.1093/icc/dtp015

Persson, O., Glänzel, W., \& Danell, R. (2004). Inflationary bibliometric values : The role of scientific collaboration and the need for relative indicators in evaluative studies. Scientometrics, 60(3), 421432.

Slaughter, S., \& Leslie, L. L. (1997). Academic Capitalism: Politics, Policies, and the Entrepreneurial University. Baltimore: The Johns Hopkins University Press.

Sørensen, M. P., \& Schneider, J. W. (2017). Studies of national research performance: A case of "methodological nationalism" and "zombie science”? Science and Public Policy, 44(1), 132-145. http://doi.org/10.1093/scipol/scw043

Thelwall, M., \& Wilson, P. (2014). Regression for Citation Data : An Evaluation of Different, 8, 963971.

Van Raan, A. F. J. (1998). The influence of international collaboration on the impact of research results. Scientometrics, 42(3), 423-428.

Waltman, L. (2016). A review of the literature on citation impact indicators. Journal of Informetrics, 10(2), 365-391. http://doi.org/10.1016/j.joi.2016.02.007

Waltman, L., Calero-Medina, C., Kosten, J., Noyons, E. C. M., Tijssen, R. J. W., van Eck, N. J., ... Wouters, P. F. (2012). The Leiden ranking 2011/2012: Data collection, indicators, and interpretation. Journal of the American Society for Information Science and Technology, 63(12), 2419-2432. http://doi.org/10.1002/asi.22708

Waltman, L., \& van Eck, N. J. (2015). Field-normalized citation impact indicators and the choice of an appropriate counting method. Journal of Informetrics, 9(4), 872-894. http://doi.org/10.1016/j.joi.2015.08.001

Waltman, L., \& Van Eck, N. J. (2013). A systematic empirical comparison of different approaches for normalizing citation impact indicators. Journal of Informetrics, 7(4), 833-849. http://doi.org/10.1016/j.joi.2013.08.002

Wuchty, S., Jones, B. F., \& Uzzi, B. (2007). The Increasing Dominance of Teams in Production of Knowledge. Science, 316(5827), 1036-1039. http://doi.org/10.1126/science.1136099 
Postprint version:

Bloch, C. W., Ryan, T. K., \& Andersen, J. P. (2019). Public-private collaboration and scientific impact: An analysis based on Danish publication data for 19952013. Journal of Informetrics, 13(2), 593-604. https://doi.org/10.1016/j.joi.2019.03.003

Supplementary Material

Supplementary Table S 1. Coefficients for regression analysis of all models presented in the study. For each coefficient we note the lower and higher bounds of the 95\% confidence interval in brackets.

\begin{tabular}{|c|c|c|c|c|c|c|c|}
\hline \multirow[b]{2}{*}{ Predictor } & \multicolumn{7}{|c|}{ Dependent variable log(ncs+1) } \\
\hline & all sciences & health_sci & eng_mat_sci & biomed & chemistry & phys_math & agri_fish_for \\
\hline (Intercept) & $-.327(-.351--.302)$ & $-.521(-.553--.489)$ & $169(-.224--.114)$ & $-.488(-.532--.445)$ & $-.435(-.513--.357)$ & $-.191(-.252--.13)$ & $-.302(-.361--.243)$ \\
\hline n_authors & $.002(.002-.002)$ & $.027(.025-.028)$ & $0(-.001-.002)$ & $.018(.016-.019)$ & $.039(.031-.048)$ & $.001(0-.001)$ & $.054(.049-.059)$ \\
\hline dk_indu & $.006(-.016-.028)$ & $-.043(-.082--.003)$ & $.072(.021-.123)$ & $-.029(-.066-.007)$ & $5-.089)$ & $.098(.021-.175)$ & $.029(-.022-.08)$ \\
\hline int_indu & $.17(.126-.213)$ & $.143(.065-.221)$ & $.127(.034-.22)$ & $.181(.102-.259)$ & $(5-.251)$ & $007-.25)$ & $152-.091)$ \\
\hline int_univ & $.196(.184-.207)$ & $.225(.205-.244)$ & $.077(.043-.11)$ & $.153(.13-.176)$ & $-.103(-.143--.062)$ & $.026(-.008-.059)$ & $.018(-.015-.05)$ \\
\hline intl_ind_uni & $97-.2)$ & $.185(.098-.272)$ & $21-.04)$ & $54-.131)$ & $7--.001)$ & $-.01(-.168-.149)$ & $-.015)$ \\
\hline YEARd1 & & - & - & & - & - & \\
\hline YEA & $-.32(-.354--.286)$ & $-.304(-.36--.249)$ & $--.064)$ & $-.351(-.419--.282)$ & $-.162(-.28--.045)$ & $31--.294)$ & $-.122(-.22--.025)$ \\
\hline YEA & & $-.297(-.352--.242)$ & $--.201)$ & & $9--.106)$ & $--.426)$ & $-.093)$ \\
\hline YEARd4 & $-.331(-.364--.298)$ & $-.266(-.321--.211)$ & $-.328(-.429--.228)$ & $-.363(-.429--.296)$ & $4--.002)$ & $-.4(-.488--.311)$ & $.283--.098)$ \\
\hline YEA & $-.312(-.344--.279)$ & $-.217(-.271--.163)$ & $-.333(-.429--.237)$ & $9--.279)$ & $(27-.09)$ & $-.42(-.508--.332)$ & $.297--.124)$ \\
\hline YEARd6 & $-.281(-.313--.248)$ & $-.192(-.245--.138)$ & $-.32(-.417--.223)$ & $1--.231)$ & $-.15(-$. & $-.387(-.476--.298)$ & - -.039) \\
\hline YEA & - - -.202) & $-.157(-.21--.103)$ & $9--.098)$ & $4--.175)$ & .059 & $-.372(-.459--.285)$ & $174--.001)$ \\
\hline YEA & $-.265(-.297--.233)$ & $-.174(-.227--.12)$ & $-.292(-.387--.197)$ & $-.28(-.344--.216)$ & $12-.096)$ & $--.373)$ & $269--.099)$ \\
\hline & & $-.147(-.199--.0$ & $-.2(-.289--.111)$ & $-.22(-$. & 3) & $-.375(-$. & $-.066)$ \\
\hline YEARd11 & $-.198(-.229--.167)$ & $-.12(-.171--.069)$ & $-.191(-.277--.105)$ & 2 - -.106) & -.037 & - -.203) & - -.104) \\
\hline YEARd & $-.193(-.224--.163)$ & $-.131(-.181--.081)$ & $-.236(-.32--.151)$ & $-.132(-.194--.07)$ & $-.003(-$. & $3--.226)$ & $-.175(-.259--.09)$ \\
\hline YEAI & $-.162(-.192--.132)$ & $-.102(-.15--.053)$ & $-.15(-.234--.066)$ & $-.159(-.22--.098)$ & $99-.122)$ & $4--.157)$ & $-.15(-.23$ \\
\hline YEARd14 & $-.126(-.155--.096)$ & $-.065(-.112--.017)$ & $-.119(-.204--.033)$ & $-.13(-.19--.07)$ & $.014(-.089-.117)$ & $-.185(-.273--.096)$ & $-.119(-.198--.04)$ \\
\hline YEARd15 & $-.103(-.132--.074)$ & $-.012(-.058-.035)$ & $-.15(-.231--.068)$ & $-.087(-.148--.027)$ & $.054(-.048-.156)$ & $-.158(-.246--.071)$ & $-.117(-.197--.036)$ \\
\hline YEARd16 & $-.096(-.124--.067)$ & $-.055(-.101--.009)$ & $-.027(-.109-.054)$ & $-.106(-.165--.047)$ & $-.019(-.119-.081)$ & $-.143(-.229--.057)$ & $-.084(-.163--.004)$ \\
\hline YEARd17 & $-.084(-.111--.056)$ & $-.055(-.1--.011)$ & $-.081(-.159--.002)$ & $-.077(-.135--.019)$ & $.022(-.077-.121)$ & $-.138(-.221--.054)$ & $-.044(-.122-.033)$ \\
\hline YEARd18 & $-.044(-.071--.017)$ & $-.004(-.047-.04)$ & $-.087(-.162--.012)$ & $-.086(-.143--.028)$ & $.045(-.049-.139)$ & $-.053(-.134-.027)$ & $-.03(-.105-.046)$ \\
\hline YEARd19 & $-.018(-.045-.008)$ & $.012(-.03-.055)$ & $-.015(-.089-.058)$ & $-.013(-.07-.044)$ & $.026(-.067-.118)$ & $-.107(-.186--.027)$ & $0(-.073-.074)$ \\
\hline YEARd20 & - & - & . & & - & 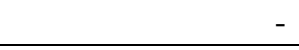 & \\
\hline
\end{tabular}

